\title{
Análisis económico de la industria de muebles de madera en Colombia con una perspectiva desde el sector forestal (1991 - 2010)
}

pags 101-113

Grupo de investigación: Desarrollo y Equidad

María Esperanza Cuenca Coral•

\section{RESUMEN}

Colombia cuenta con un potencial en la producción de madera, ya que cuenta con suelos fértiles y gran diversidad de árboles maderables "El país tiene una superficie total cercana a los 114 millones de hectáreas; de ellas algo más de 60 millones disponen de cobertura de bosques naturales, lo que equivale al 55\% del territorio nacional colombiano, y solo 405.000 hectáreas corresponden a bosques plantados de las cuales cerca de 377.000 tienen fines comerciales" (Minagricultura, 2011).

Palabras clave: Análisis económico, Muebles de madera, Sector forestal

\begin{abstract}
Colombia has a potential timber production, as it has fertile soils and a variety of timber "The country has a total area close to 114 million hectares; of which more than 60 million have coverage of natural forest, equivalent to $55 \%$ of Colombia's national territory and only 405,000 hectares are planted forests which about 377,000 have commercial purposes" (Minagricultura, 2011).
\end{abstract}

Key words: Economic analysis, Wooden Furniture, Forestry Sector

- Docente investigadora Universidad de América. Economista M.Sc. maria.cuenca@investigadores.uamerica.edu.co 


\section{INTRODUCCIÓN}

Es interesante saber que de acuerdo con la Corporación Colombiana Internacional (2000), "El mercado de los productos forestales es el tercero en importancia a nivel mundial, después del petróleo y el gas. Este sector aporta entre el $2 \%$ y el $3 \%$ del producto interno bruto mundial y representa el $3 \%$ del comercio internacional de mercancías." (Pizarro, 2003).

Debido a los pocos estudios realizados sobre la cadena forestal - muebles de madera, se decidió analizar los impactos que tiene esta industria sobre el sector forestal en el país. Además conocer sobre la producción de muebles de madera, teniendo en cuenta su desempeño a nivel nacional como internacional, por medio de la producción nacional, las importaciones, exportaciones y la balanza comercial.

Asimismo se muestran otro tipos de materias primas con las cuales se pueden fabricar muebles y que están teniendo auge tanto a nivel nacional como internacional, como lo son el bambú y el mimbre, que son materiales que necesitan menos tiempo para madurar y poder ser usados.

Es importante destacar que se puede alcanzar un desarrollo sustentable por medio de industrias como la de muebles de madera, ya que por medio de la reforestación se puede generar un autoabastecimiento para que este tipo de producción no afecte el bosque natural sustituyendo los árboles que han sido talados.

\section{MATERIALES Y MÉTODO}

\section{Industria de muebles de madera}

Las industrias forestales son aquellas que usan maderas extraídas de bosques naturales o plantados, es decir que son industrias maderables, como las empresas que producen celulosa y papel, así como aquellas que fabrican, tableros aglo- merados de todo tipo, chapas, contrachapados, muebles con madera aserrada y combustible.

Como se observa en la Figura 1, planteada por el Departamento Nacional de Planeación (DNP), a partir de la madera en bruto o también llamado trozas, es decir la madera que se extrae del bosque natural o de la plantación forestal, genera diferentes eslabones como la madera aserrada o madera inmunizada, que es utilizada para generar bienes como muebles.

\section{Cadena productiva}

Para la producción de muebles de madera se debe empezar por la explotación de madera en bosques naturales o plantaciones forestales. Las empresas que estén interesadas en realizar este proceso para la producción de muebles deben acogerse a la ley forestal y de esta manera especificar la especie que desean extraer.

\section{Eslabones de muebles de madera}

Los eslabones involucran el cultivo de árboles, que son el medio en donde crece y se desarrolla la materia prima, posterior a este proceso es extraída la madera con el fin de que esta sea transformada y finalmente generar productos de buena calidad.

En esta cadena productiva el primer eslabón que se tiene en cuenta para la fabricación de muebles de madera son los proveedores de insumos del sector forestal, es decir, se encargan de proporcionar semillas para los cultivos de árboles.

Para llevar a cabo esta etapa la cadena productiva de muebles de madera, primero se debe realizar un estudio del suelo para identificar si es apto para la siembra de árboles, luego se seleccionan las semillas, finalmente estas son plantadas y después de 15 o 20 años se obtienen los árboles, que posterior a este proceso son tomados como la materia prima para la fabricación de muebles. 
Figura 1. Estructura simplificada de la cadena productiva, madera y muebles de madera

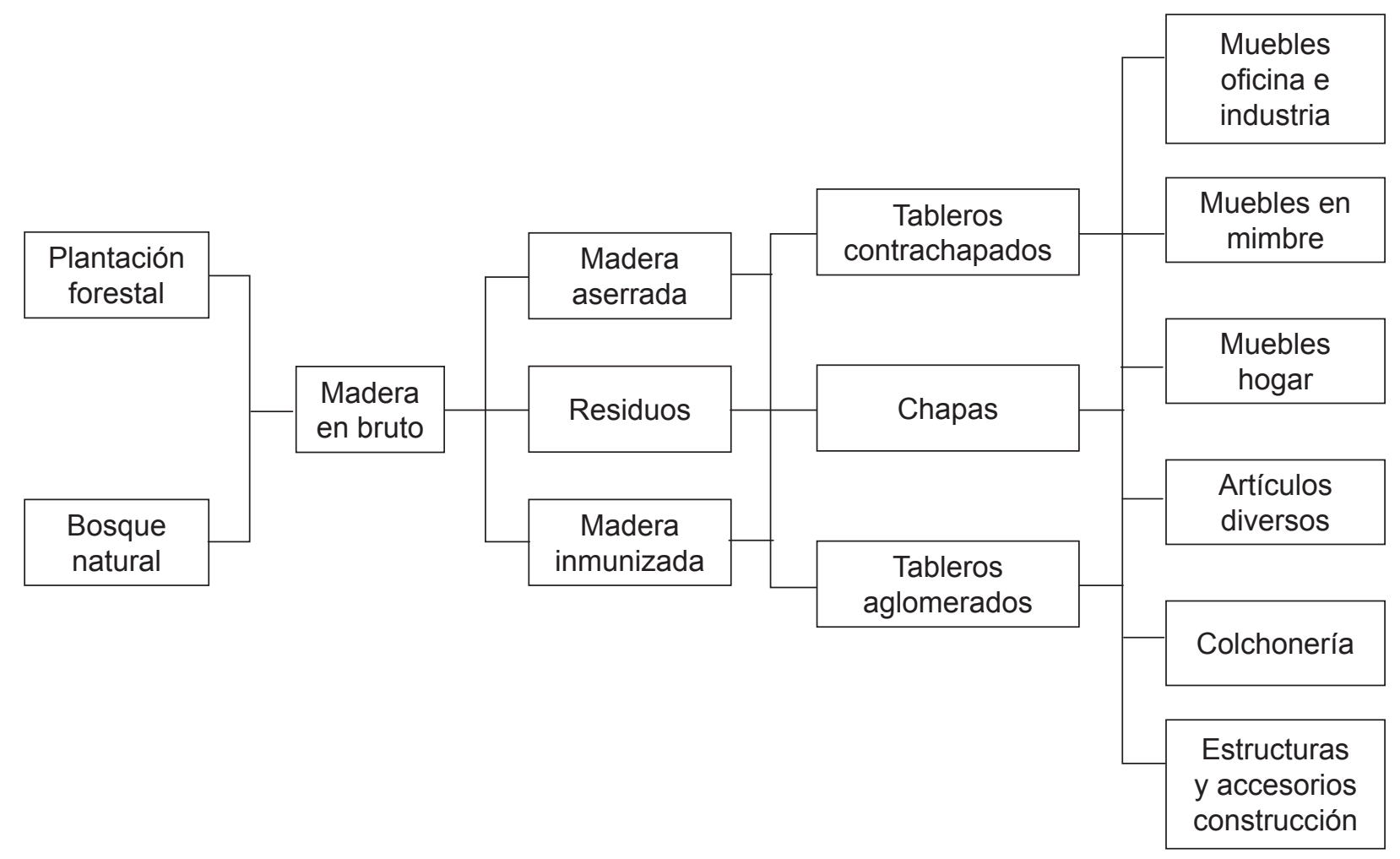

Fuente: Departamento Nacional de Planeación (DNP)

Figura 2. Modelo de la cadena forestal madera - muebles de madera

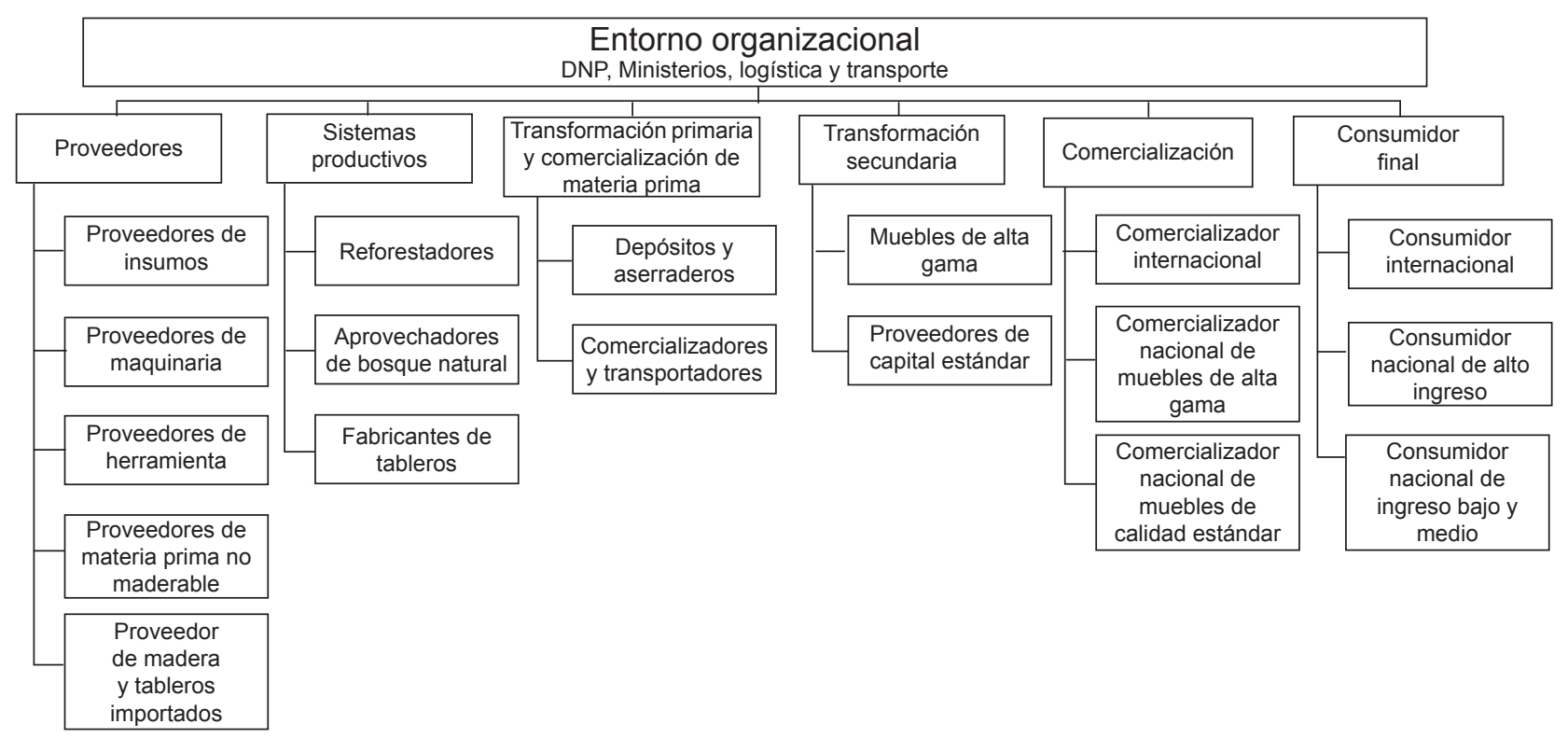

Fuente: Ministerio de Agricultura y Desarrollo Rural 
La cadena productiva de muebles de madera toma como eslabones:

- Proveedores.

- Productores de materia prima o sistemas productivos.

- Transformadores primarios y comercializadores.

- Transformadores secundarios.

- Comercializadores y consumidores.

En la Figura 2 se muestra es eslabonamiento de la cadena productiva de los muebles de madera.

\section{Producción nacional de muebles de madera}

Se entiende como mueble "a todo elemento que esté pensado, diseñado y construido a fin de ser utilizado en el espacio de una vivienda o edificación con diferentes usos de acuerdo a su forma o propósito. Una de las características básicas a la hora de definir lo que es un mueble es, justamente, el hecho de que es un objeto movible que puede ser trasladado de un lugar a otro, por lo cual otros objetos relacionados con la construcción y la decoración no pueden ser considerados muebles (por ejemplo, ventanas, puertas, techos, pisos, paredes y otros)." (DefinicionABC, 2012)

Colombia posee una gran diversidad de productos hechos con madera, entre ellos los muebles, en los que podemos encontrar escritorios, sillas, mesas, sofás, pupitres, bibliotecas, archivadores, entre otras clases.

Según la Encuesta Anual Manufacturera (EAM), la producción y venta nacional de la industria, entre los que se encuentra los diferentes muebles hechos a partir de madera. Dentro de la encuesta se encuentran las empresas que alcanzaron una producción superior a $\$ 500.000$ pesos durante el año. El histórico se encuentra desde 1992, en el cual se encuentran cuarenta y nueve productos considerados muebles de madera.

A partir de 1994 se agregaron dos muebles más a la producción nacional según la EAM, los muebles de madera para escuelas y sillas de madera para teatros. En 1996 se incluyó los muebles de madera para radio. En 1998 las papeleras de madera para oficina ingresaron dentro de producción nacional.

Desde el 2000 se hace una variación en la EAM en la cual se quitan algunos productos como muebles de madera para radios, muebles de madera para televisores, muebles de madera para radiolas, muebles de madera máquinas de coser, muebles de madera para bafles y amplificadores de sonido, silla de madera para la sala, poltronas de madera para la sala y sofás de madera para la sala, sillas de madera para comedor, sofá-camas, butacas de madera para alcoba, sillas de madera para oficina, sillas giratorias de madera, sillas de madera para restaurante y servicios análogos, bancos de madera para iglesias, sillas de madera para teatros, butacas de madera. Para este año se unificaron los productos en conjuntos más generales y se crearon nuevas categorías como guardarropas-closets, cocinas integrales, muebles integrales para restaurante y servicios análogos y otros muebles de madera.

1. Muebles de madera para televisores

2. Muebles de madera para radiolas

3. Muebles de madera para máquinas de coser

4. Muebles de madera para bafles y

5. Amplificadores de sonido

6. Sillas de madera para sala

7. Poltronas de madera para sala 
LÍNEA DE INVESTIGACIÓN: DESARROLLO INDUSTRIAL Y EMPRESARIAL

8. Sofás de madera para sala

9. Mesas de madera para sala

10. Muebles de madera n. e. p. para sala

11. Sillas de madera para comedor

12. Mesas de madera para comedor

13. Aparadores de madera

14. Muebles de madera n. e. p. para comedor

15. Camas de madera

16. Sofá - camas

17. Mesas de noche de madera

18. Peinadores o tocadores de madera

19. Cómodas -armarios- de madera

20. Butacas de madera para alcoba

21. Camarotes de madera

22. Muebles de madera n. e. p. para alcoba

23. Muebles especiales de madera para baño

24. Escritorios de madera

25. Mesas de madera para oficina

26. Sillas de madera para oficina

27. Sillas giratorias de madera

28. Archivadores de madera

29. Bibliotecas de madera

30. Vitrinas de madera para oficina

31. Muebles modulares para oficina
32. Muebles de madera N.E.P. para oficina

33. Mostradores de madera

34. Vitrinas de madera

35. Muebles de madera N.E.P. para el comercio

36. Mesas de maderas para restaurantes y servicios análogos

37. Sillas de madera para restaurante y servicios análogos

38. Muebles de madera n. e. p. para servicios

39. Pupitres de madera sencillos

40. Pupitres de madera dobles

41. Sillas-pupitre

42. Tableros de madera para escuelas

43. Bancos de madera para iglesias

44. Mesas de madera para dibujo

45. Butacas de madera

46. Papelógrafos de madera

47. Estantes de madera

48. Gabinetes, módulos de madera para

49. Cocina integral

50. Muebles en madera para cocinas integrales

51. Muebles N.E.P. de madera

La unidad de medida varía según el artículo, para la mayoría se maneja en $\mathrm{N}$ que es el número de unidades, para otros productos, como estantes de madera, gabinetes, módulos de madera para cocina integral y muebles de ma- 
dera para cocinas integrales se mide en metros cuadrados (M2), mientras que los muebles de madera se miden en volumen $(\mathrm{V})$.

\section{Balanza Comercial}

Para el periodo 2006-2010 la balanza comercial de Colombia ha sido superavitaria, se ha evidenciado que el país ha exportado muebles de madera a países como Venezuela, Estados Unidos y Panamá. Uno de los eventos que incidieron en la reducción de exportaciones hacia Venezuela para el año 2008 fue la crisis diplomática por la que atravesaban los dos países como se observa en la siguiente Gráfica 1.

La demanda de muebles de madera en el entorno internacional ha aumentado, ya que Estados Unidos se caracteriza por ser el principal país de destino de exportaciones de muebles de madera en Colombia, además es el país que mejor remuneración otorga a por la producción de estos bienes, las empresas que más exportan muebles de madera en Bogotá, las más representativas son: I.M.A industria de artículos de madera S.A, Impropera, Industrias Exporenso S.A, C.I Selecta LTDA, diseño y acabados Rochs LTDA.
La comercialización de muebles de madera se realiza por medio del transporte marítimo, terrestre y aéreo. Los costos más altos en que se incurren en el momento de tranzar estos bienes, se presentan mediante el transporte aéreo ya que se tiene en cuenta para enviar muebles de madera a los países que se encuentren más cerca a Colombia, mientras que si se realiza exportaciones por medio del transporte marítimo los costos en que se incurre son menores y los bienes son entregados en países que se encuentran retirados de Colombia como es el caso de Estados Unidos, España, Holanda, Israel y Rusia

Uno de los factores más importantes que inciden en el proceso de transacción de muebles de madera son los acuerdos comerciales, ya que tienen la finalidad de reducir aranceles en el momento en que un bien sea transferido al país de destino. En el caso de Colombia los tratados que benefician la producción de muebles de madera son la Asociación Latinoamericana de integración (ALADI) y el Sistema Generalizado de Preferencias (SFP); mediante este último acuerdo la partida arancelaria demás muebles de madera se benéfica en mayor medida, ya que el en el momento de realizar la transacción comercial el arancel es cero.

\section{Gráfica 1. Balanza Comercial de Muebles de madera 2006-2010}

$$
\text { Exportaciones Importaciones Balanza comercial }
$$

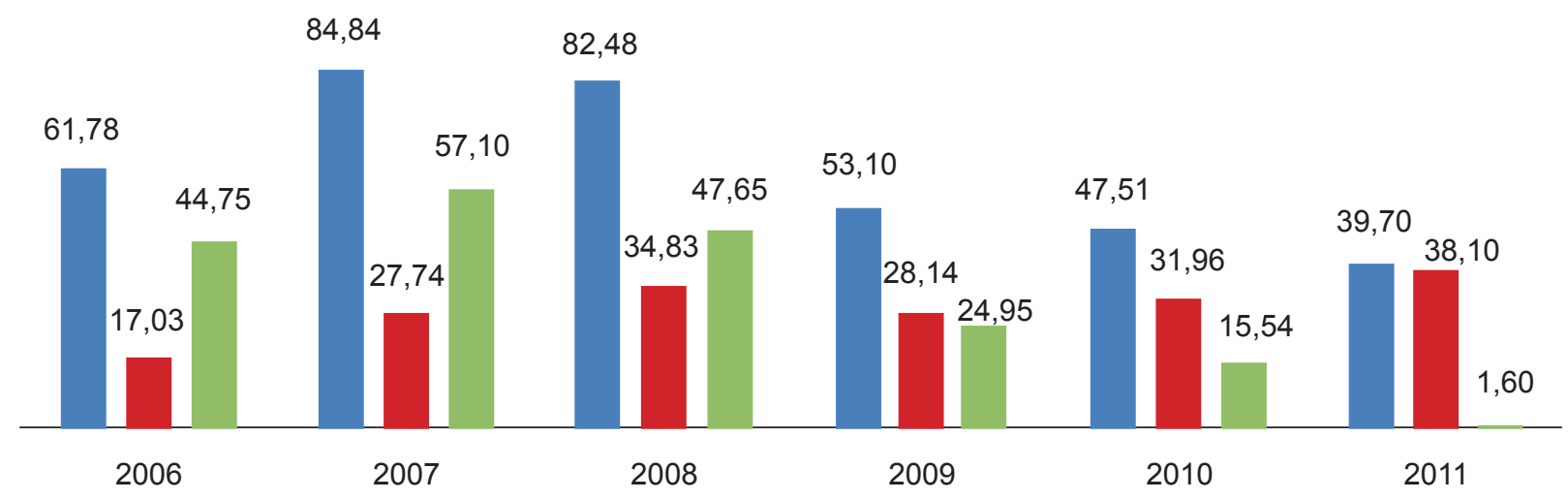

Fuente: Siex, Cálculos Proexport. 
LÍNEA DE INVESTIGACIÓN: DESARROLLO INDUSTRIAL Y EMPRESARIAL

Desarrollo sustentable de muebles

Debido a que la materia prima que se usa para la producción de muebles de madera, se extrae de los bosques naturales, y teniendo en cuenta que se quiere tener un desarrollo sustentable en el país, la propuesta que se da por medio de este estudio, es la reforestación comercial, por medio de la cual se obtienen insumos para los productores de muebles.

Además se observa que se pueden utilizar otras materias primas como el mimbre y el bambú para producir muebles, que son materiales que poseen características físicas y químicas que las hacen resistentes, asimismo maduran en un periodo más corto de tiempo, comparativamente con los árboles.

\section{Reforestación comercial}

Como se describe en el decreto 1498 de 2008 y el decreto 1791 de 1996, "La reforestación comercial se comprende como el cultivo de árboles en el cual hubo intervención del hombre sobre estos bosques y que a su vez son comercializados como productos madereros o subproductos de esta materia prima" (Constitución Política de Colombia).

El gobierno se ha enfocado en la reforestación por medio de incentivos para la inversión forestal creados para estimular a la población a plantar bosques tanto comerciales como protectores.

Para la plantación forestal hay diferentes recursos de fomento como los créditos, en el cual se debe mostrar un proyecto viable que deben presentar los reforestadores a un intermediario financiero para adquirir el crédito. Hay diferentes condiciones financieras para adquirir financiación, dependiendo las características que posea el productor. "Según la línea de inversión para siembra y renovación de bosques, con una financiación hasta del 80 por ciento, con relación al total de los costos directos de la inversión, y con un plazo acorde al ciclo productivo del cultivo y una tasa de interés de acuerdo al tipo de productor." (Marín, 2010) Para los pequeños productores en el 2010 se estableció una tasa de interés máxima de DTF efectivo anual más el 6 por ciento, mientras que para el productor mediano y grande se creó una tasa de DTF más 10 por ciento para créditos con plazos iguales o superiores a 10 años.

Los incentivos y las exenciones son mecanismos creados por el Gobierno para incentivar la plantación comercial, es una de las herramientas que más usan los reforestadores, ya que "tiene un efecto económico positivo en la rentabilidad de la inversión y contribuyen a mantener y hacer viable las plantaciones comerciales." (Marín, 2010).

El incentivo más importante es el Certificado de Incentivo Forestal (CIF), el cual consiste en el pago del $50 \%$ de las plantaciones introducidas y el $75 \%$ para especies autóctonas, el cual es financiado por hasta 5 años, desde la siembra hasta el mantenimientos de las especies, este procedimiento se hace por me del Ministerio de Agricultura y Desarrollo Rural y Finagro es el organismo que gira el dinero del presupuesto nacional dedicado a este programa. El Incentivo a la Capitalización Rural (ICR) es un abono no reintegrable que hace Finagro del Presupuesto Nacional, para que los productores paguen el crédito de maquinaria y equipo. Este programa puede abonar el $20 \%$ para productores medianos o grandes, y para productores pequeños hasta el $40 \%$, los cuales son los más favorecidos, ya que si no tienen recursos disponibles, estos serán beneficiados con el programa. Además existen exenciones tributarias para los productores comerciales forestales, como deducciones del impuesto de renta, que son una manera de incentivar a las personas a plantar árboles. Según los proyectos que se han diseñado en el país entre 1995 y 2012, se han plantado 229.950 hectáreas de bosques comerciales con una inversión de $\$ 391.556$ millones como se demuestra en el CONPES 3793. 
Gráfica 2. Distribución anual de áreas reforestadas e Inversiones

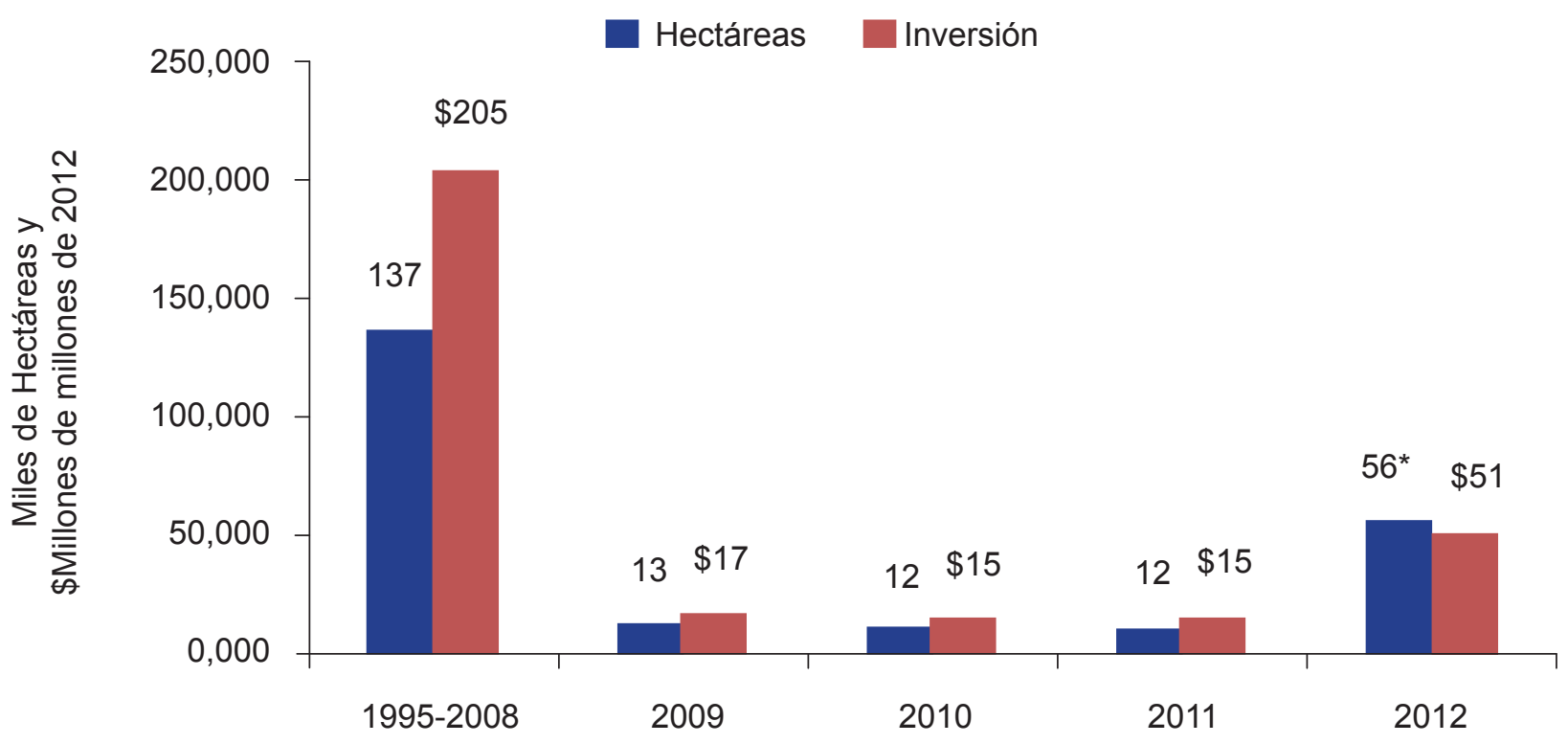

Fuente: CONPES 3793, Base de datos CIF. MADR. Dirección de Cadenas

Como se observa en la Gráfica 2 se ha invertido hacia el sector forestal una cantidad de dinero significativo que puede aprovechar el país, aunque Colombia tiene un gran potencial forestal que no se ha explotado de manera eficiente, por lo tanto está en la capacidad de reforestar más áreas. Según el Plan de Desarrollo del Presidente Juan Manuel Santos "Prosperidad para todos" se espera que para el 2014 se hayan plantado 600.000 hectáreas de bosques comerciales.

Otros materiales para producir muebles

Teniendo en cuenta que la extracción de madera en Colombia es indiscriminada, se puede optar por otro tipo de muebles que poseen características y diseños diferentes, los cuales están hechos con materias primas como el bambú y el mimbre, que son materiales que tienen la ventaja de crecer en menor tiempo que la madera y además poseen propiedades de durabilidad y resistencia.

\section{Muebles de bambú}

La planta más demandada dentro de las clases de bambú es la guadua, este es un material que es usado por diferentes sectores en la economía, se usa como materia prima y para uso industrial. En Colombia este producto tiene grandes potenciales para su aprovechamiento, debido a que es un material que no necesita tanto tiempo para crecer y madurar, aunque falta mayor intervención tecnológica en los procesos de producción y transformación.

La guadua fue denominada como "acero natural" debido a sus propiedades físicas como su dureza y la facilidad con la que se puede manejar este material, por eso es usado para construir muebles, debido a que posee características que favorecen al medio ambiente. La guadua tiene usos domésticos como para construir cercas, para evitar deslizamientos, como canalizador de agua. 
LÍNEA DE INVESTIGACIÓN: DESARROLLO INDUSTRIAL Y EMPRESARIAL

El uso de este material aumentó después del terremoto en el eje cafetero registrado en el año 1999, debido a sus propiedades como dureza y sismo resistencia. En vista de los beneficios que proporciona la guadua, se observa que aproximadamente el $86 \%$ del área natural y plantada de guaduales lo aporta esta zona. Según los datos registrados por el Ministerio de agricultura y desarrollo rural, se observa que alrededor del $87 \%$ de los guaduales son naturales y el $13 \%$ restante corresponde a hectáreas plantadas.

\section{Muebles de mimbre}

El mimbre es una fibra vegetal que se obtiene de un arbusto de especies que hacen parte de la familia sauces salix, los tallos de estas plantas son gruesos, en el momento de cultivar mimbre se debe seleccionar un área que posea un clima templado. En Colombia las zonas aptas para cultivar esta especie deben tener una temperatura promedio de 15 a 23 grados centígrados, el mimbre crece entre 1.200 y 1.800 metros sobre el nivel del mar.

Según la información del programa Nacional de cadenas productivas en el sector Artesanal de Colombia (2006), se puede inferir que la producción del mimbre es un mercado pequeño; ya que las personas que se benefician en esta cadena productiva son 170; que están representados en Ibagué: 67 hombres y 3 mujeres y en Silvania: 85 hombres y 15 mujeres.

La cadena productiva del mimbre tiene cuatro eslabones los cuales son; los cultivadores, artesanos y como último eslabón se hace referencia a la producción y comercialización de esta planta. En mayo del año 2013 el gobierno nacional (eltiempo.com, 17 de mayo de 2005), ha implantado un programa con el fin de generar más empleo y que se creen más empresas, la idea de este proyecto es vincular a los artesanos que tengan iniciativa y compromiso con la producción de bienes a partir del mimbre.
Impactos de la industria de muebles de madera en el sector forestal

Según el estudio realizado por el DANE (2011) en su dirección de cuenta satélite del medio ambiente llamado Cálculo piloto de los Flujos físicos y monetarios de productos del bosque, en el cual se determina extracción de madera en los bosques de Colombia. Este estudio se basa en la obtención de productos maderables que se generan desde la silvicultura como lo es la leña, la madera aserrada y los tableros de madera, no se tienen en cuenta maderas en bruto, ni madera para pasta.

Los muebles de madera están hechos con bienes intermedios como la madera aserrada y los tableros de madera. Como se observa en la Gráfica 14 la leña es el mayor demandante de unidades físicas del bosque, en el 2000 alrededor de 6.639.178 Toneladas de la madera que se uso fue utilizada como leña, mientras que la madera aserrada tan solo empleo 159.742 Toneladas y 141.078 Toneladas para la creación de tableros.

Aunque disminuyo entre el 2000 y el 2010 la madera utilizada como leña fue insignificante, ya paso de ocupar el $95.67 \%$ a $93.21 \%$. Por el contrario el uso de madera para la creación de tableros aumento de $2.03 \%$ en el 2000 a $4.94 \%$ en el 2010.

Es así como en el 2010 el uso de madera para leña fue de 6.762.695 Toneladas, de madera aserrada fue de 134.406 Toneladas y tableros 358.602 Toneladas. Aunque la leña utilice gran parte de las unidades físicas que provienen del bosque, no es un gran productor de unidades monetarias.

Como se observa en la Gráfica 4 los resultados de las estadísticas sobre las unidades monetarias de madera extraída del bosque es muy diferente a la anterior (Gráfica 3), ya que se muestra que un gran porcentaje del uso de madera está destinado a la leña, es de menor valor, mientras que se usa menos madera para la creación de tableros tiene mayor valor en unidades monetarias. 
Gráfica 3. Utilización de productos del bosque en unidades físicas 2000-2010

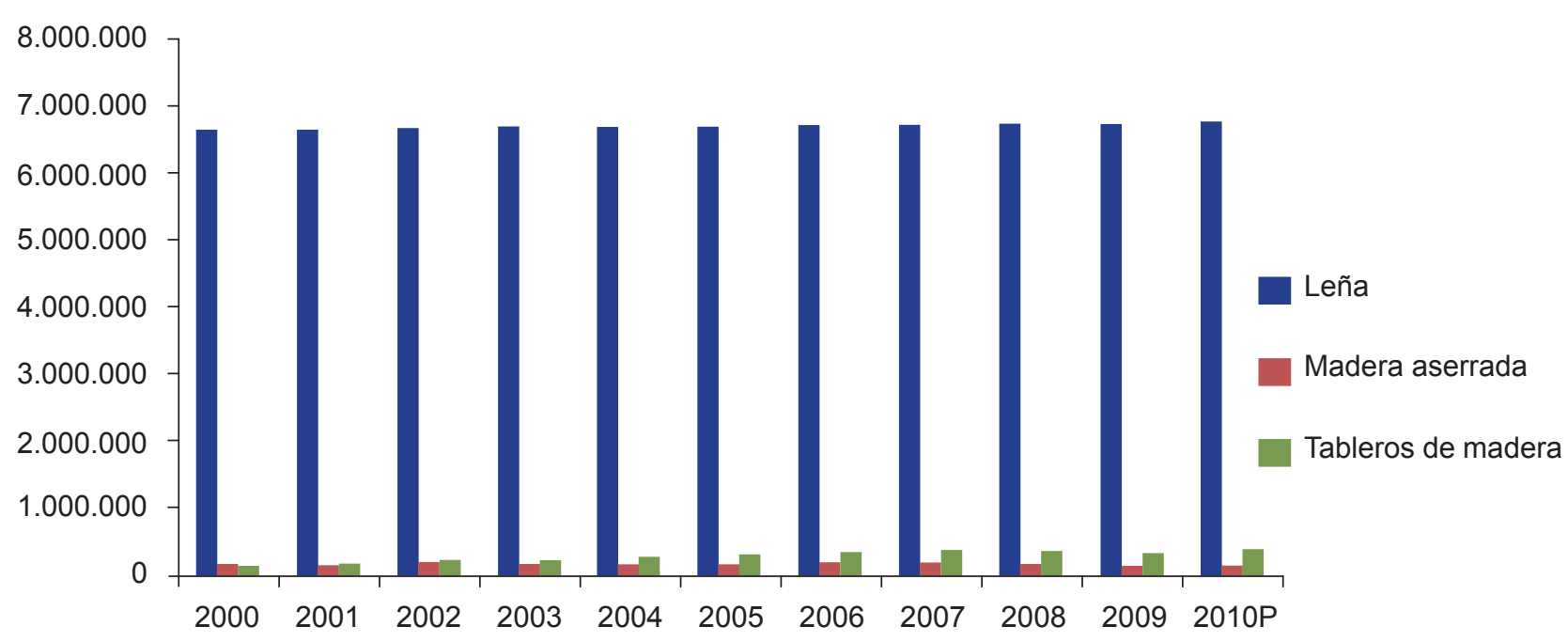

Fuente: Departamento Administrativo Nacional de Estadística (DANE),

Gráfica 4. Utilización de productos del bosque en unidades monetarias 2000 - 2010

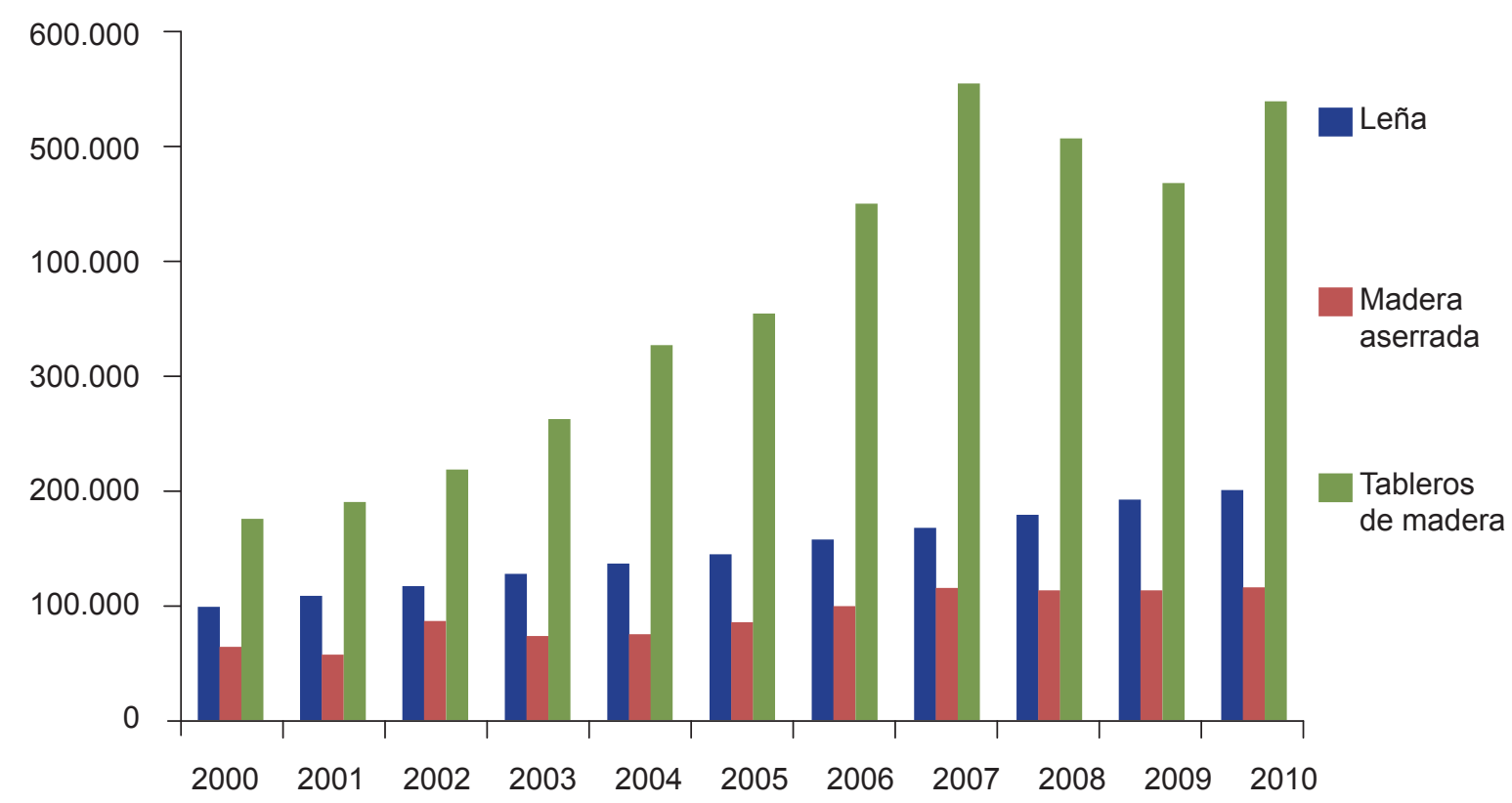

Fuente: Departamento Administrativo Nacional de Estadística (DANE).

Entre el 2000 y el 2010 se observa un aumento en cuanto a todas las variables estudiadas, siendo el mayor generados de unidades físicas los tableros, seguido de la leña y finalizando la madera aserrada. 
LÍNEA DE INVESTIGACIÓN: DESARROLLO INDUSTRIAL Y EMPRESARIAL

En el 2000 se generó 342.565 millones de pesos corrientes a precios básicos por la utilización de productos del bosque, los cuales 178.101 millones corresponden a tableros de madera, 100.512 millones a leña y 63.952 millones a madera aserrada.

En el 2010 alrededor del $63.02 \%$ de la utilización de los productos del bosque pertenece a tableros de madera con 542.601 millones de pesos corrientes, mientras que la leña ocupa el $23.34 \%$ con 200.942 millones y la madera aserrada alrededor de $13.65 \%$ por un valor de 117.490 millones.

\section{CONCLUSIONES}

Por medio de este estudio se demostró que la industria de muebles de madera es viable en el país, debido a la riqueza natural que posee Colombia como tierras productivas y prosperas que hacen que el crecimiento de los árboles se presente en menos tiempo comparativamente con otros países. Además esta industria posee grandes expectativas a nivel mundial, ya que goza de un gran mercado, donde hay muchos demandantes.

Para disminuir el impacto sobre el medio ambiente se quiere estimular a que las empresas y personas para que empleen la plantación comercial, contribuyendo así al desarrollo sustentable para la producción forestal como lo son los muebles en madera. Se debe tener en cuenta que hay diferentes opciones para conseguir el capital necesario para esta inversión como los medios de financiación, estímulos y exenciones tributarias.

La cadena productiva tiene un largo proceso que relaciona eslabones, que se inicia desde la plantación forestal o la extracción de madera en el bosque natural, de allí se obtiene la madera en bruto que después será procesada dependiendo del uso que se le quiera dar y de esta manera se obtiene madera aserrada, residuos y madera inmunizada. Mediante el proceso de productivo se obtienen bienes intermedios como los tableros contrachapados, chapas, tableros aglomerados y con estos productos se fabrican muebles de madera para oficina, industria, hogar, cocina, entre otros.

Es importante mencionar que para la producción de muebles de madera se emplean bienes intermedios como por ejemplo la madera en rollo, madera aserrada y tableros de madera. Esta industria saca al mercado sillas, mesas, sofás, pupitres, bibliotecas y archivadores.

En Colombia el centro de muebles más importante en el país es Bogotá, ya que cuenta con más del $40 \%$ de la producción nacional, en segundo lugar se encuentra Medellín, Cali, Popayán, Pasto, y en último lugar la Costa Atlántica, que cuenta con menos del $10 \%$ de la producción nacional.

El mercado de muebles de madera está conformado por empresas que se encargan de la producción de este tipo de bienes, un punto negativo de esta industria es que algunas empresas son informales, debido a que no están registradas en la cámara de comercio, no pagan impuestos y no cumple con el pago de las prestaciones sociales a los trabajadores.

Para contrarrestar esta situación en Colombia existen entidades que se encargan de capacitar a las personas por medio de la artesanía para la producción de muebles, como por ejemplo el SENA, en donde son orientados sobre el proceso productivo para la fabricación de muebles, también son capacitados para que produzcan muebles con excelentes diseños, esta entidad los motiva a que constituyan empresas dedicadas a esta actividad y las formalicen.

Después de una política proteccionista, a principios de los noventa Colombia adoptó un modelo que consistió en que el mercado nacional se inundó de bienes producidos por el país, este hecho trajo como consecuencia que las personas perdieran la capacidad de poder adquisitivo. 
Además los precios de los bienes nacionales empezaron a aumentar y el nivel de competitividad en el país disminuyo. El presidente Cesar Gaviria implanto la política de apertura, que tuvo como efecto la introducción de bienes producidos en países extranjeros, por lo tanto en Colombia muchas industrias dedicadas a la producción de muebles de madera desaparecieron del mercado nacional y empezó a aumentar la importación de este tipo de bienes.

Otro hecho importante en la fabricación de muebles de madera en Colombia, se presentó en el año 2001 ya que el país experimento la mayor producción, debido a las transformaciones que se presentaron en la política comercial que tenían como propósito eliminar las barreras al comercio exterior, además se implanto una reforma del régimen de licencias de importación y una reforma arancelaria. Por medio de estas políticas en Colombia se aumentaron los niveles de producción de muebles de madera y como consecuencia se incrementó el nivel de exportación de este tipo de bienes.

Para el periodo 2006-2010 la balanza comercial de Colombia ha sido superavitaria, se ha evidenciado que el país ha exportado muebles de madera a países como Venezuela, Estados Unidos y Panamá. Es importante mencionar que Colombia mantuvo una relación comercial estable con Estados Unidos durante el periodo de estudio.

La industria de muebles de madera atravesó por una difícil situación en el año 2008, ya que el nivel de exportaciones se redujo hacia Venezuela debido a la crisis diplomática que enfrentaba dicho país con Colombia.

Con el transcurso del tiempo la industria de muebles de madera a nivel nacional se ha fortalecido, como resultado a esta situación se ha exportado mayor cantidad de muebles de madera fabricados para ser utilizados en oficinas, cocinas y dormitorios.

En cuanto a los impactos que genera la industria de muebles de madera en el sector forestal se concluye que según la información brindada por el DANE aproximadamente más del 92\% de la madera entre el 2000 y el 2010 es usada como leña, mientras que el porcentaje restante es usado para la obtención de madera aserrada y tableros de madera, que son productos usados para la creación de muebles de madera.

Lo que concluye que los bienes que son usados para elaborar muebles de madera no tienen impactos grandes sobre el sector forestal en el país, en cuanto a las unidades físicas un gran porcentaje de los productos del bosque son usados como leña.

\section{RECOMENDACIONES}

Colombia debería realizar un control sobre las empresas que se dedican a la producción de muebles de madera con el fin de tener conocimiento sobre las compañías que están operando de manera informal y de esta manera incentivarlas para que se constituyan legalmente. Si se logra que estas empresas se formalicen, los trabajadores de estas industrias tendrán mayores beneficios en cuanto a las prestaciones sociales y obtendrán una remuneración mayor a la que se le otorga actualmente.

En cuanto al entorno internacional es importante que Colombia siga manteniendo buenas relaciones comerciales con Estados Unidos, ya que es el principal receptor de muebles de madera debido a la alta demanda que experimenta este país. El mercado estadounidense adquiere muebles de madera fabricados en Colombia porque la mano de obra que se emplea para la producción de estos bienes es especializada, además los productos poseen finos acabados.

Implantar incentivos fiscales para la industria de muebles de madera; con el fin de que las empresas no adquieran madera ilícita. Gracias a esta medida se busca que los fabricantes de muebles de madera utilicen para su producción materia prima extraída mediante los parámetros establecidos por la ley. 
LÍNEA DE INVESTIGACIÓN: DESARROLLO INDUSTRIAL Y EMPRESARIAL

Al realizar este estudio se tuvo dificultad al encontrar la información necesaria para realizar un análisis econométrico, debido a que según los registros que se poseen a nivel nacional son escasos, o son poco explícitos para realizar un análisis riguroso. Además hubo dificultad en el momento de buscar información pertinente al periodo de estudio, ya que se encuentra de manera fragmentada. Según el Ministerio de Ambiente y Desarrollo Sostenible se está haciendo un gran esfuerzo para generar información anual sobre el estado de los bosques naturales y plantaciones forestales.

\section{BIBLIOGRAFIA}

Constitución Política de Colombia; decreto 1498 de 2008 y el decreto 1791 de 1996.

DANE (2011) Cálculo piloto de los Flujos físicos y monetarios de productos del bosque. Dirección de Síntesis y Cuentas Nacionales DSCN.

Definición ABC (2011). Definición de muebles, Documento en línea: disponible en: http://www.definicionabc.com/general/mueble. php\#ixzz2VvqJHmgZ

Salazar, G. (2010). Programa Nacional de Conformación de Cadenas Productivas para el sector Artesanal Colombiano, Págs. 39-41

Marín, C. (2011). Financiación forestal, estímulos y exenciones, Revista M\&M; Edición 67; Págs. 32-35. Documento en línea. Disponible en: http:// www.revista-mm.com/edicio- nes/rev67/forestal_financiacion.pdf

Ministerio de Agricultura y Desarrollo Rural (2011). Minagricultura alerta por saqueo de los bosques naturales del país y un posible conflicto entre el sector agrícola y minero, 3-5. Documento en línea. Disponible en: http:// www.minagricultura.gov.co/ archivos/_bol_167_minagricultura_alerta_por_saqueo_de los_bosques_naturales_del_ pais_y_un_posible_conflicto_ entre_el_sector_agricola_y_ minero.pdf

Ministerio de Agricultura y Desarrollo Rural (2007). Cadena productiva forestal -tableros aglomerados y contrachapados -muebles y productos de madera, Pág. 30. Documento en línea. Disponible en: http:// www.minagricultura.gov.co/archivos/forestal.pdf

Muebles Domoticos. Secado artificial de piezas en madera método artificial. Noviembre
3 de 2010; Documento en línea. Disponible en: http:// mueblesdomoticos.blogspot. com/2010/11/secado-al-hornode-maderametodo.html

Pizarro, J. (2003) Productos forestales. Productos Forestales. Corporación Colombia Internacional $(\mathrm{CCl})$

Panorama general del sector. Perfil del producto ,1-2: Documento en línea. Disponible en: http://www.cci.org.co/ cci/cci/perfil\%20producto $\% 20$ 23.pdf

Vásquez, G. (2011). Los bosques plantados y la huella hídrica, la respuesta hidrológica y la hidrosolidaridad. Universidad Nacional Medellín. Ministerio de Agricultura. Documento en línea: http://www. mtnforum.org/sites/default/ files/pub/pantaciones_y_bosques_doc._sectorial_forestal. pdf 